\title{
Medicinal plants of the Chinese \\ Pharmacopoeia and Daodi: insights from phylogeny and biogeography
}

Article

Accepted Version

Creative Commons: Attribution-Noncommercial-No Derivative Works 4.0

Lei, D., Wu, J., Leon, C., Huang, L.-f. and Hawkins, J. A. (2018) Medicinal plants of the Chinese Pharmacopoeia and Daodi: insights from phylogeny and biogeography. Chinese Herbal Medicine, 10 (3). pp. 269-278. ISSN 1674-6384 doi: https://doi.org/10.1016/j.chmed.2018.06.004 Available at https://centaur.reading.ac.uk/78030/

It is advisable to refer to the publisher's version if you intend to cite from the work. See Guidance on citing.

To link to this article DOI: http://dx.doi.org/10.1016/j.chmed.2018.06.004

Publisher: Elsevier

All outputs in CentAUR are protected by Intellectual Property Rights law, including copyright law. Copyright and IPR is retained by the creators or other copyright holders. Terms and conditions for use of this material are defined in the End User Agreement.

www.reading.ac.uk/centaur 
Central Archive at the University of Reading

Reading's research outputs online 


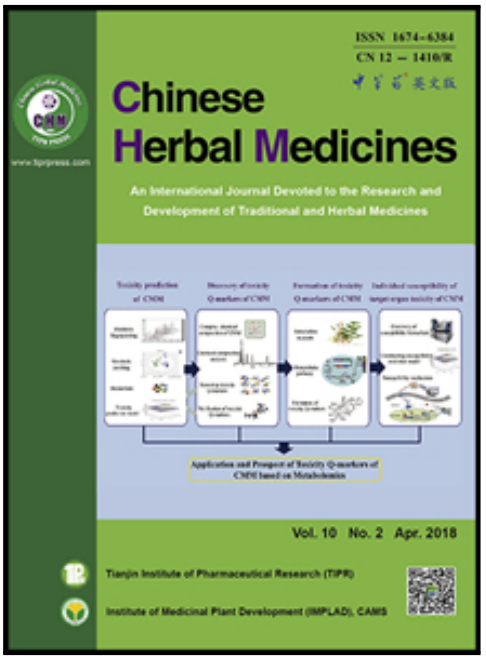

Medicinal plants of Chinese Pharmacopoeia and Daodi: insights from phylogeny and biogeography

Di Lei , Jie Wu, Christine Leon, Lin-fang Huang , Julie A. Hawkins

PII:

DOI:

S1674-6384(18)30069-8

Reference:

To appear in:

Received date:

Revised date:

Accepted date: 10.1016/j.chmed.2018.06.004

CHMED 45
Chinese Herbal Medicines

Please cite this article as: Di Lei, Jie Wu, Christine Leon, Lin-fang Huang, Julie A. Hawkins, Medicinal plants of Chinese Pharmacopoeia and Daodi: insights from phylogeny and biogeography, Chinese Herbal Medicines (2018), doi: 10.1016/j.chmed.2018.06.004

This is a PDF file of an unedited manuscript that has been accepted for publication. As a service to our customers we are providing this early version of the manuscript. The manuscript will undergo copyediting, typesetting, and review of the resulting proof before it is published in its final form. Please note that during the production process errors may be discovered which could affect the content, and all legal disclaimers that apply to the journal pertain. 


\section{Medicinal plants of Chinese Pharmacopoeia and Daodi: insights from phylogeny and biogeography}

Di Lei ${ }^{1}$, Jie $\mathrm{Wu}^{2}$, Christine Leon ${ }^{3}$, Lin-fang Huang ${ }^{4}$, Julie A. Hawkins ${ }^{1} *$

1. School of Biological Sciences, University of Reading, Reading RG6 6BX, United Kingdom

2. Institute of Chinese Materia Medica, China Academy of Chinese Medical Sciences, Beijing 100700, China

3. Royal Botanic Gardens, Kew, Richmond, Surrey TW9 3AB, United Kingdom

4. Institute of Medicinal Plant Development, Peking Union Medical College \& Chinese Academy of Medical Sciences, Beijing 100193, China

\section{ABSTRACT}

Objective The Chinese Pharmacopoeia (2015) includes 584 plant medicines, of which 284 also contain high quality subsets, so called "Daodi" components, where Daodi denotes superior clinical properties compared to non-Daodi counterparts despite being sourced from the same species. Commercial and clinical drivers of selection for Daodi have been described elsewhere. Our objective is to investigate the overall composition of Daodi to determine in what ways medicines with Daodi as a whole differ from the other plants of the Chinese Pharmacopoeia. A further objective is to characterise the Chinese Pharmacopoeia and Daodi in terms of the plant species including their traits and distribution.

Methods We used trait analysis to identify whether Daodi species were significantly different from the remaining Chinese Pharmacopoeia plant species in any traits. We used biogeographic methods and an existing classification of Daodi into 10 regions to identify spatial patterns amongst the species. Regression and binomial analyses were used to test for over- and under-use of plant families and endemic species. Preferences for lineages were visualized using phylogenetic mapping.

Results We found Daodi species (species with any Daodi subset) were more likely to be roots that are 'hot' or 'warm', and less likely to be 'toxic', according to traditional Chinese medicine (TCM) concepts. Roots were over-represented in the Bei region, and whole plants over-represented in Guang. Both the Chinese Pharmacopoeia and Daodi indicated preferences for families not common in previously studied ethnopharmacopoeias, and fewer endemic species were represented than expected by chance.

Conclusion Utsing the phylogenetic and biogeographical methods, we highlighted patterns of plant use, and the biological characters of Daodi medicinal plants. Our study points towards cultural preferences in need of scientific explanation. 


\section{Introduction}

Ethnopharmacology may play an important role in the discovery of new drugs (Balick and Cox, 1996, Heinrich, 2000). Understanding how medicinal plants are selected for local use or incorporated into written pharmacopoeias may contribute to understanding of plant efficacy (Browner, 1985, Heinrich et al., 1998, Gorji, 2003, Leonti et al., 2017). There are different approaches to deepening the scientific understanding of how plants are selected for use; cross-cultural studies have been put forward as one powerful way of identifying plants of particular utility, particularly if they discriminate between transmission of knowledge and independent discovery (Heinrich et al., 1998, Saslis-Lagoudakis et al., 2014, van Andel et al., 2014), and new tools are being added to existing ones to make such comparisons (SaslisLagoudakis et al., 2012). We set out here to use systematic tools not to make cross-cultural comparisons, but to make comparisons within China, using information about plant traits, plant distribution and plant taxonomy and phylogeny. This allows us to consider spatial aspects of plant selection, and to compare the subset of medicinal plants referred to as Daodi with the other plants of the Chinese Pharmacopoeia. The characterisation of the plants in this way can inform studies of transmission of knowledge and ultimately bioprospecting.

The Daodi is a subset of traditional Chinese medicine (TCM) materials that meet the highest quality criteria (Hu, 1989). They are the most frequently used medicines, and since the 1980s, of more than 11000 crude drugs, the subset of approximately 200 Daodi medicines accounted for more than $80 \%$ of the market share in China (Qian, 1987; Pan 2011). The 200 Daodi medicines include plants, animal products, and minerals. The Daodi medicinal material is from designated geographic regions where conditions including climate, soil, and techniques of cultivation (in the case of plants) and harvesting and processing are thought to confer clinical superiority (Zhao et al., 2012). The concept of Daodi medicinal materials has been compared to the concept of "terroir" (Leon and Yu-Lin, 2017), where the French term was used to describe the environmental conditions of soil and climate that confer superiority on wines of a region, but is now more widely used to indicate the unique characteristics and quality of produce that are regional specialities. In the case of Daodi, the conditions in the regions are thought to confer clinical superiority, and for this reason Daodi medicines are considered the most efficacious.

The etymology of "Daodi" derives from the "Dao", administrative regions in ancient China. The "Di" refers to the land where the plant or animal grows, or where the mineral can be found (Hu, 1989). The Daodi concept appeared in the very first Bencao (materia medica), Shennong Bencao Jing (ca. 2 BCE), which established regions for production as well as seasons for collecting and processing. It also briefly records the different eco-environments of medicinally-used plants, for example as "mountain valleys", "river valleys" or "along the big lake". The names of medicines reflected the Daodi characters at the time, for instance "Badou" (Crotonis fructus), "Shujiao" (Zanthoxyli pericarpium), "Qinpi" (Fraxini cortex) and "Wuzhuyu" (Evodiae fructus), where "Ba", "Shu", "Qin", and "Wu" refer to the regions. The regions referred to in the Shennong Bencao Jing were ones already established as administrative regions in the time of the Zhou dynasties (ca. 2000 BCE). However, it was only with the prosperity of Zhenguan in the Tang Dynasty (618 CE), and the concomitant increase in trade, that the 10 "Dao" with the best quality medicines were officially approved by the central government. The phrase "Daodi" as understood today was first mentioned and widely used in the Ming dynasty. In the official pharmacopeia Bencao Pin Hui Jing Yao (1505 CE), there are 268 out of 916 medicines with specific Daodi region (Huang and Wang, 2015; Hu, 1989).

Over the centuries, the composition of the Daodi medicinal material has changed, and locations for production of Daodi have changed too. The Daodi localities themselves may be rather narrow, and there may be more than one. Daodi regions are broad-scale regions, roughly mapping to administrative regions, to which Daodi medicines can be assigned. There have been different concepts of Daodi regions. Today there are ten Daodi regions (following Hu's 1989 classification: Guan, Bei, Huai, Zhe, Nan, Guang, Yun, Gui, Chuan, and Xi). In the Tang dynasty, there were already 10 "Dao", but they refer to different areas. Even when a region's name is conserved, the specific area may change or it may contain different Daodi medicine species. For example, the "Guan" region where Daodi Panax ginseng C.A.Mey is cultivated, was not part of China in the Tang dynasty. At that time, the best Chinese Panax ginseng was produced from Shangdang area in Shanxi Province, which falls into today's "Bei” region. Despite the clinical and economic importance of Daodi, Daodi have never been explicitly included in any edition of the People's Republic of China Pharmacopoeia.

Scientific evidence to support the alleged clinical superiority of Daodi medicinal material are the subject of ongoing research (Huang and Wang, 2015). Zhao et al. (2012) identified external and internal factors, where superior germplasm was an external factor and internal factors included suitable environmental conditions, cultivation and processing. Huang and Wang (2015) reviewed research fields that would corroborate traditional practices, providing a scientific basis for the Daodi medicinal material, including pharmacological and "omic" studies. These studies show considerable promise for explaining the scientific basis of Daodi superiority. We take a different approach, since better understanding of the way in which Chinese medicinal plants have been selected may contribute to the wider understanding of plant efficacy. Daodi medicines have not been the focus of a comprehensive, systematic review that considers their taxonomic, phylogenetic, and biogeographic origins.

In this study, we make a review using the Latin scientific species names that are assigned to the Daodi medicines included in a recent pharmacopoeia, specifically the 2015 pharmacopoeia (Chinese Pharmacopoeia Commission, 2015). Using the review and the existing data describing the Daodi regions, we are able to address novel questions about the overall composition of Daodi. Phylogenetic methods are emerging as tools to understand the relatedness of medicinal plants (Saslis-Lagoudakis et al., 2012). We present a phylogeny that shows the 
relationships of Daodi plants for the first time, and we ask whether there are preferred lineages of plants included in Daodi. As well as considering Daodi as a whole, in comparison to the whole Chinese Pharmacopoeia, we characterise each Daodi region. We consider whether the regions differ in medicinal characters, in terms of the traits of the plants associated with each region.

\section{Materials and Methods}

\subsection{Data compilation}

We built a Daodi medicines dataset, including contemporary Latin scientific plant species names and the following additional traits: part of plant used, nature, flavour, toxic or not, target organ, and Daodi regions. Daodi medicines and Daodi regions were recorded from two books (Hu, 1998 and Hu, 1998). The medicine name was used as an identifier to assign Linnaean identifications and other traits of each medicine using the People's Republic of China Pharmacopoeia, 2015 edition. All the non-pharmacopoeia medicines were removed from the final dataset.

\subsection{Characterising environment of Daodi regions}

Using the GADM database of Global Administrative Areas (2012, version 2.0) to delimit areas, we mapped the 10 Daodi regions. Daodi origins are usually very specific for each medicine, but it is widely accepted that specific Daodi origins can be clustered and assigned to areas referred to as Daodi regions. We characterised each Daodi region bio-climatically according to the vegetation types represented, following the Vegetation map of the People's Republic of China 1:1 000000 (Zhang, 2007). We produced a map indicating the altitudinal range of these Global Administrative Areas using ArcGIS (ESRI, 2011), and produced a map and indicated the bio-climatic range within which each Daodi species must be found using knowledge of the distribution of Daodi regions in Administrative areas.

\subsection{Trait distributions}

We tested the hypotheses that Daodi plants were overall provisioning different traits compared to the whole Pharmacopoeia, and that traits were significantly more likely to be associated with different regions. We used our compiled dataset of Daodi medicines and their areas to extract lists showing the frequency of traits associated with the medicines of each region. The traits were those associated with the Daodi medicines according to the treatments for the pharmacopoeias, and including tastes, natures, and whether the plants are toxic or not. We also scored the therapeutic targets or channels of each medicine, and the part of the plant used for each medicine. Using the lists of traits compiled, we used Fisher's exact test to determine whether there were significant differences between the number of Linnaean species used as medicines with specific traits in the Chinese Pharmacopoeia and the number of Linnaean species used as medicines with those traits in the Daodi medicinal material. The null hypothesis is that the probability of finding plants with specific traits or therapeutic targets is the same whether or not a species has a subset with Daodi. We expect non-random distribution of traits, since it may be more important to know the origins of poisonous plants, or of medicines where the plant parts used, such as roots, are more difficult to identify. The test was conducted in Minitab 17 Statistical Software (2010) using the '2 proportions' function. We also compared the number of traits associated with the medicines of each Daodi region, to test whether any trait was over-represented in any region. To obtain the distribution patterns, we first use the 'cross tabulation and Chi-square', analysis in Minitab 17. For each trait, the analysis returns two pieces of information: A likelihood ratio Chi-square value to indicate whether the trait is equally distributed among 10 Daodi regions, and a factor of contribution to the Chi-square value is given to each region in every analysis. $P$-values were calculated from each Chi-square value with a degree of freedom of nine by applying the formula CHISQ.DIST.RY in Excel 2017.

\subsection{Taxonomic and phylogenetic composition

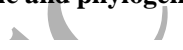

We carried out two approaches to investigate the taxonomic and phylogenetic distribution of Daodi species (species with a subset with Daodi), and to determine whether there are Pharmacopoeia or Daodi botanical families over and under-represented compared to the Flora of China (FOC). The first used methods were described by Moerman (1991), and developed further by Bennet and Husby (2008). The analyses were performed at the family level. Following Moerman's (Moerman, 1991) method, this is a way of highlighting groups that are over/under- represented in a medicinal flora. Those with extreme positive values are used more frequently, and those with extreme negative values are used less frequently than expected. Outliers were identified using the interquartile range (IQR) of the distribution of $r$ values. Positive outliers are those with $r$ values 1.5 times the IQR or more above from the third quartile (Q3 $+1.5 \times \mathrm{IQR})$, negative outliers are those with $r$ values 1.5 times the IQR or less, below the first quartile $(\mathrm{Q} 1-1.5 \times \mathrm{IQR})$. Binomial analyses as described by Bennett and Husby (2008) are not as commonly applied as regression analysis although they share the same objective; Binomial analysis highlights families that depart from a uniform model of proportion of medicinal plants in each flora. Binomial analyses were carried out in Microsoft Excel, following Bennett and Husby (2008). We used a checklist of the Flora of China to extract the numbers of species in each Botanical Family. Then, for the Chinese Pharmacopoeia and subset of Daodi species, we tested whether there were over- and underused families. For comparative purposes, outliers from published analyses of the ethnofloras of Nepal, South Africa Cape, and New Zealand were also shown (Saslis-Lagoudakis et al., 2011). 
Secondly, in order to visualise the lineages preferentially selected for use in the 2015 Chinese Pharmacopeia and in the Daodi materia medica, a species phylogenetic tree was constructed in R 3.4.2 (R Development Core Team, 2013) with the "phytools" package (Revell, 2011) using the function S.PhyloMaker (Qian and Jin, 2015). The backbone of the tree and nodes was obtained together with the S.PhyloMaker script (Qian and Jin, 2015). The tree was visualized and annotated in iTOL (Letunic and Bork, 2016).

\subsection{Role of endemic species in composition of Daodi}

In order to know whether Daodi plants are more or less endemic than the plants of the Chinese Pharmacopoeia or Flora of China we assessed relative proportions of endemism. Every Linnaean species was scored according to whether it is endemic to China or not using the published list of Huang et al., (2011) as a reference. Each species was also scored against the Chinese invasive alien species list using the assessment of Weber et al.(2008). We summarised the findings, identifying the Daodi regions that include the most endemic species, and those that incorporate invasive aliens.

\section{Results}

3.1 Daodi regions and medicinal traits distributions in each region

The map of the Daodi regions was shown in Fig. 1, and the climatic and ecological variation found in the regions was exhibited in Table 1. Daodi are unevenly distributed across China, for example Nan is much smaller than Xi but is the source region of many Daodi plants. Six Daodi regions, Bei, Huai, Nan, Zhe, Gui and Chuan, are limited to only one vegetation type. Guan and Xi, the largest regions span four and five vegetation types respectively. Considering the 34 plant traits, 21 are significantly unevenly distributed amongst the ten different Daodi regions (Table 2). However, there are only nine traits which show significantly different distributions between all Daodi plants in total and the remainder of the Chinese Pharmacopoeia. There are more significantly hot and warm plants with pericardium and bladder as target organ amongst Daodi. There are fewer whole plants and flowers, but fruits and seeds and roots are found more often in Daodi. The full distribution of plant traits was shown in Table 2, indicating comparisons between the Chinese Pharmacopoeia and Daodi, and between the different regions of Daodi.

3.2 Phylogenetic visualization and regression analyses of family preferences

The positive and negative (outliers plant families which are proportionally over-used or under-used considering the family size and compared to the overall rate of use) as recovered from regression analyses of the Chinese Pharmacopoeia and Daodi species were shown in Table 3. The regression equation parameters and graphs for Chinese Pharmacopoeia and Daodi species are in appendix a. Table 2 showed selected families with the greatest positive or negative residual from the regression analyses, these are the most over- or under- used families respectively. The top 3 over-used families in Daodi are Liliaceae, Apiaceae, and Ranunculaceae. In comparison to outliers from published analyses of the ethnofloras of Nepal, South Africa Cape, and New Zealand (Saslis-Lagoudakis, 2011), none of these is outlier in the medicine flora of other three countries. Of the Daodi top 10 families, two families, Magnoliaceae and Araceae are not outliers in any of the other floras. In the Chinese Pharmacopeia, the top 3 families are Fabaceae, Rutaceae, and Liliaceae. Asteraceae, Lamiaceae, and Cucurbitaceae are all ranked more highly families in the Chinese Pharmacopeia than Daodi. The families Gesneriaceae, Saxifragaceae, Primulaceae, Ericaceae, Orchidaceae, Cyperaceae, and Poaceae are all underused. Fig. 2 showed the phylogenetic distribution of Chinese Pharmacopoeia and Daodi species, indicating that Daodi are distributed throughout the phylogeny.

3.3 Endemic and invasive species of Chinese Pharmacopeia and Daodi medicinal plants

Daodi plants include a higher proportion of plant species that are endemic to China than the Chinese Pharmacopeia, but both the Chinese Pharmacopeia and Daodi include far fewer endemic plants than the Flora of China as a whole. Table 4 described the proportion of plants that are endemic to the Flora of China, to the Chinese Pharmacopoeia and to each of the Daodi regions. The proportion of endemic species used in Daodi varies from zero (no endemic plants used) to $27 \%$ of plants endemic. The Chinese Pharmacopoeia is more likely to include an alien invasive species than the Flora of China overall.

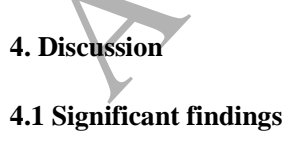

This study has used a suite of methods not previously applied to the Chinese Pharmacopoeia or Daodi, and pointed towards factors that might influence species represented in Daodi, aside from the regional differences in clinical efficacy. Ultimately studies at the species level, characterising the relationships between intraspecific variation, environment, and efficacy, including pharmacological and "omic" studies, are needed to provide a scientific basis for Daodi (Huang and Wang, 2015). Our findings can be grouped into four main areas for further discussion. Firstly, we have highlighted differences in traits between Daodi plants and the reminder of the plants species included in the Chinese Pharmacopoeia. We put forward hypotheses to account for these differences. Secondly, we have shown how plants with different traits are found in different regions, and we discuss how this might be attributed to floristic and climatic differences. Thirdly, we find preferences for lineages amongst plants of Daodi and the Chinese Pharmacopoeia. Finally, we find fewer endemic species are represented in 
Daodi and the Chinese Pharmacopoeia than expected by chance. We discuss how transmission of knowledge might underlie a preference for widespread species.

\subsection{Traits of Daodi compared to remainder of Chinese Pharmacopoeia}

Daodi species are significantly more likely to be sourced from roots (underground parts other than bulbs, including roots, rhizomes, tubers etc.) than other species in the Chinese Pharmacopoeia without Daodi representatives. Roots are the most commonly occurring plant part in the Chinese Pharmacopeia 2015 (>30\% of total), and over-representation of roots in Daodi could be because roots are more often substituted. One example of a substituted root is Shashen. Originally, Shashen is sourced from Adenophora tetraphylla (Thunb.) (Campanulaceae), but in the $17^{\text {th }}$ Century as long distance trading became more common, Glehnia littoralis (A. Gray) F. Schimidt ex Miq. (Apiaceae) became the preferred source of Shashen (Leon and Yu-Lin, 2017). The Daodi prefixes would help the users to distinguish between the two Shashen, with Beishashen (Glehnia littoralis) from the Bei Daodi region, and Nanshashen (Adenophora tetraphylla) sourced from the Nan Daodi region. There are many examples of Daodi prefixes applied to roots, but it is unusual that both species are Daodi. Examples of substitutes where one species is named with a region prefix include Niuxi (Achyranthes bidentate Blume; Amaranthaceae) and Chuanniuxi (Cyathula officinalis Kuan; Amaranthaceae), Muxiang (Aucklandia costus Falc.; Ásteraceae) and Chuanmuxiang (Vladimiria souliei (Franch.) Shih; Asteraceae) and Shegan (Iris domestica (L.) Goldblatt \& Mabb.; Iridaceae) and Chuanshegan (Iris tectorum Maxim.; Iridaceae). The designation of Daodi to distinguish substitute species may be particularly prevalent because roots are hard to identify; designating region of origin to distinguish between substitutes would be desirable if one were preferred over the other because of perceived clinical superiority. Roots are challenging for herbalists to identify; Studies of Moroccan medicinal plants have shown that herbalists may find roots hard to identify (Ouarghidi et al., 2012). Knowing that the roots were sourced from a region where roots were plentiful might increase confidence in their identities. Another possible explanation for over-representation of roots in Daodi compared to other plants of the Chinese Pharmacopoeia is that accumulation of biological actives in roots is more variable according to climatic and edaphic conditions. There are few studies demonstrating the effects of climate or soils on phytochemistry; One such study showed that roots grown in high altitude environments are more phytochemically active (Kishore et al., 2010).

Daodi are also more significantly likely to be 'hot' or 'warm'. Only 13 TCM herbs (sourced from 15 Linnaean species) are recorded as 'hot' medicinal herbs in Chinese Pharmacopeia 2015, while 11 TCM species (13 Linnaeus species) are in Daodi material medicines. Comparing to the rest of non-Daodi species in Chinese Pharmacopeia 2015, there is a prevalence for the 'pericardium' and the 'bladder' (these target organs are in the TCM target energy systems which are not the clinical equivalence). In total, 34 species target the 'bladder' of which 28 are 'warm'. The prevalence of these target organs may be attributed to the high representation of TCM medicinal plants classified as 'hot' and 'warm'. Notably, six of the fifteen medicinal plants in pharmacopoeia that are classified as 'hot' have toxic character as well. There is no such thing as a totally safe medicine, as has been widely discussed in many Traditional Chinese Medicine books, including the Inner Cannon of the Yellow Emperor. Safety issues have always been a core concern relating to clinical use of plants. Now explicit legal requirements for safety of plant medicines, alongside requirements of efficacy and repeatability, are enshrined by the Chinese Food and Drug Administration (CFDA, 2014). Safety is also a key factor in new drug development (Xue et al., 2013). We expected toxic medicinal used plants to be over represented in Daodi species, since there is evidence that some species show intra-specific variation in presence of toxic compounds (for example in Acorus L. (Bertea et al., 2005)), and any information that might help differentiate toxic and non-toxic material might be of great value. However, contrary to our expectations, fewer Daodi species were toxic. Notably, scoring of "toxic" was according to the 2015 Chinese Pharmacopeia, and does not correlate with scientific understanding of toxicity. For example, Senecios candens Buch.-Ham. Ex D.Don, well known to be poisonous (Fu et al, 2002) is not considered toxic according to TCM. More research is need to explore the natures and tastes, target organs and the toxic categories, both from a historical and emic perspective, and also from an etic perspective that includes consideration of the mode of aetion of the plants.

\subsection{Traits of Daodi compared between regions}

Daodi regions are artificial units that encompass the narrow Daodi-specific localities, and which map to administrative regions rather than explicitly biogeographic ones. Nevertheless, these regions showed climatic and ecological differences (Table 1). Although the biogeographical analysis is at a very coarse scale, and bearing these caveats in mind, we found differences in the distribution of the plant parts used amongst regions. Aerial parts/whole plants and roots are unevenly distributed amongst the areas, with an over-representation of roots from Guan and Zhe, and under-representation from Guang. In contrast, aerial parts/whole plants are over-represented in Guang and under- represented in Guan. This might be explained by the different ecological environment of Daodi regions, while cultural and historical influence may also result in uneven distribution. Studies suggest that roots grown in high altitude environments are more phytochemically active (Kishore et al., 2010), but the scale of our study is not sufficient to test whether altitude drives quality assessments of roots. However, our findings could be related to the ecology of the regions: Guang is in the tropical and subtropical area which is the most comparable region to tropical southeast Asia, while Guan represents the temperate and cold temperate zone with relative high altitude mountain areas. The preference for aerial parts/whole plants is documented in other tropical regions. Ethnobotanical studies from Malay peninsula and southern India found that fewer medicinal roots and more aerial part or whole plants are used by local people (Jamal et al., 2011, Al-Adhroey et al., 2010, Sivasankari et al., 2013). There are also examples of preferences for roots in the Himalayas. For instance, northern India, Pakistan, 
and Nepal, people prefer to use roots as medicine (Kala et al., 2004, Uniyal et al., 2006, Shrestha and Dhillion, 2003). More studies are needed to tease apart the effect of culture, climate, and species composition on preference for plant parts. However, we also indicate a preference for roots in Zhe, and in this case, there does not appear to be a need to invoke culture, climate or species composition to explain why there are significantly more species contributing roots sourced from this region. In the case of Zhe one genus from this region, Cucurma L., contributes four Linnean names, and each species accounts for two Chinese medicinal names. Complex taxonomy explains the apparently high proportion of roots from Zhe.

\subsection{Preferred families in Chinese Pharmacopoeia and Daodi}

There is emerging appreciation that both intraspecific genetic variation and conditions of growth (edaphic or climatic) contribute to the quality of the herbal medicine produced (Tan et al., 2015). Indeed, the production of highest-quality medicinal plant materials under the Daodi system may depend on the selection of plants as well as on growing conditions, though the contribution of these two possibly interacting factors has yet to be determined. The focus on intraspecific variation to understand this variation as a criterion for Daodi status is the prevalent way of considering selection (Huang and Wang, 2015). Here we consider plant selection at a higher taxonomic level.

Liliaceae, Apiaceae, and Ranunculaceae are notably the top three families in Daodi but are not of significant importance in other countries studied in this way (Moerman et al., 1999, Saslis-Lagoudakis et al., 2011). They are also included in the top ten families of the Chinese Pharmacopoeia, but Apiaceae and Ranunculaceae in particular are less important, ranked $8^{\text {th }}$ and $10^{\text {th }}$. This might be because the important species or lineages in Chinese medicine have restricted distribution, and species elsewhere are of less value. Medicinally used Liliaceae, Ranunculaceae, and Apiaceae species have restricted distribution in China, and according the Flora of China some have wild or naturalized species in the east of Russia, Mongolia, Korea, Japan, Himalayan Asia, and tropical Asia. Few species have distribution beyond Asia, one such species being Cnidium monnieri (L.) Cusson. Restricted distribution might be the main reason why these species are not present in other studied countries. An alternative explanation relates to different cultural preferences. Phylogenetic studies at the level of the family, and including medicinal use of these families outside of China, is needed to better understand these patterns.

\subsection{Patterns of endemicity: imported plants and transmission of knowledge}

Both Daodi and the Chinese Pharmacopeia have fewer endemics than expected, given the very high proportion (49\%) of endemism in the Flora of China. In contrast, less than $15 \%$ of plant species included in the 2015 Chinese Pharmacopeia are distributed only in China. The endemicity of both Daodi plants and the plants of the Chinese Pharmacopoeia could be attributed to plants from outside of China have being incorporated into the Chinese body of medicinal plant knowledge, for example Saffron (Crocus sativus) and Mu Xiang (Aucklandia costus) are non-native species in cultivation. There are also examples of imported species being cultivated in China and becoming invasive, for example there are three species of Daodi that are considered invasive aliens: Aloe vera (L.) Burm. f. (Luhui in Chinese) in Guang, and Vaccaria segetalis (Neck.) Garcke (Wangbuliuxing in Chinese) and Cannabis sativa L. (Huomaren in Chinese) in Bei region typify the incorporation of non-native plants. Alien invasive species represent less than $1 \%$ of the whole flora and the same percentage of the Daodi, but these species represent more than 3\% of the latest edition of the Chinese Pharmacopoeia suggesting cultivation of non-native plants for medicine giving rise to the establishment of an invasive alien.

Low endemicity of Daodi and Chinese Pharmacopoeia plants could also be attributed to a preference for plants native to China but also distributed outside of China (Tan 2016). This could be because widespread species are often ecological weeds, and it is well known that medicinal plants include many ecological weeds (Weber et al., 2008). Use of ecological weeds is attributed to the availability of the plants, where availability facilitates medicinal use. The medicinal properties of a more widespread plant have more opportunity to be discovered, and following discovery, knowledge of medicinal use might spread across a species' range. In support of the view that traditional knowledge of Chinese medicinal plants is shared outside of China, our data show that the lineages of plants preferred in China are more like those of Nepal than those of the other regions, South Africa and New Zealand. One route by which exchange of knowledge might be notable is the Silk Route.

Many researchers have argued that Tibetan medicine combines Indian, Chinese, and Western systems of medical thought (Beckwith 1979; Stein 1972; Meng et al., 2009). Inspection of Table 3 reveals some interesting insights into the taxonomic composition of the Chinese Pharmacopoeia, and the Daodi subset of species relative to the Chinese Pharmacopoeia. The Fabaceae is the most important family in the Chinese Pharmacopoeia, and is also important for Nepal, though not significantly important for the Cape of South Africa, nor for New Zealand. The relationship between Chinese and Nepalese rankings might be due to shared traditional knowledge between these two regions, or to the presence of the same important lineages. There are several other families that like Fabaceae are important in China and Nepal, but not in South Africa or New Zealand. These are the Rutaceae, Zingiberaceae and Cucurbitaceae.

Comparing levels of endemism in Daodi with level in the Chinese Pharmacopoeia shows there are significantly more endemic species in Daodi than in the Chinese Pharmacopeia. It seems that Daodi includes few imported species because it takes a long time to establish clinical superiority of a subset of the plants. For example, South American chilli pepper (Capsicum annuиm L.) was introduced into China in the end of $16^{\text {th }}$ century. It is recorded as medicinal species in the CP 2015 but it has never been recognized as a Daodi species. Conversely, nutmeg 
(Myristica fragrans Houtt.) was introduced before the $3^{\text {rd }}$ century, from Indonesia yet nutmeg is recognised as having a Daodi component sourced from the Daodi region Guang.

Daodi regions differ in the number of Daodi and Chinese Pharmacopeia species that are endemic to China, with an average of $19 \%$ of Daodi species that are endemic, and regional difference ranging from $0 \%$ to $31 \%$. The Chuan region has the highest endemism, since it includes 32 Daodi species and 10 of them (ca 31\%) are endemic to China. On the other hand, the Yun region has no Daodi species that are endemic to China at all. It is one of three regions that has a lower percentage of endemic Daodi species than the percentage of endemic species in the Chinese Pharmacopoeia overall, the others being Nan and Guan. Yun might be expected to contribute a higher proportion of endemic species because it includes the Hengduan biodiversity hotspot, with many endemic species (Xing \& Ree, 2017). Surprisingly few of these endemic species are contributing to Chinese medicine. It also should be noticed that in total Chuan has more than twice as many Daodi species than Yun (Hu 1989,1998). The low contribution from Yun may be because medicinal species from Yun have not been accepted in the official TCM system, so they were not included in the Chinese Pharmacopeia. Weckerle et al. (2009) reported Bai people, an ethnic group living in Shaxi (Yunnan Province, Yun region), use similar plants as rest of China, suggesting that culture and knowledge might be lost from this area.

\section{Conclusions}

This study, despite focusing above the level of species, characterises Daodi taxonomically and in terms of traits, as a subset of the Chinese Pharmacopoeia which itself has preferences for families not revealed in other studies of ethnopharmacopoeias. At the same time, whilst this highlights the unique character of the Chinese Pharmacopoeia, our study of endemicity suggests transmission of knowledge. More in depth studies about the influences of global and Eurasian traditions of the evolution on the Chinese Pharmacopoeia, and vice versa, are needed. These might be at the level of the whole Pharmacopoeia, or focus on specific species and lineages. A cross cultural study of concepts of plant properties in the context of belief about health will play an important role in characterising unique and shared aspects of Chinese plant use. Phylogenetic tools can contribute to the interpretation of emerging patterns. Together, the studies outlined here contribute to understanding the historical influence of Chinese plant use, but may also contribute to the concepts beginning to be addressed in the new Belt and Road Initiative which aims, inter alia, to become a roadmap for the global realisation of the value of Chinese plant knowledge into the future.

\section{Conflict of interest}

The authors declare no conflict of interest.

\section{Acknowledgements}

This work is supported by grants from the National Natural Science Foundation of China (81473315), Public welfare scientific research project of State Administration of traditional Chinese Medicine (201507004-2-1) and CAMS Innovation Fund for Medical Sciences (CIFMS) (No. 2016-12M-3-015).

\section{References}

Al-Adhroey, A.H., Nor, Z.M., Al-Mekhlafi, H.M., \& Mahmud, R. (2010). Ethnobotanical study on some Malaysian anti-malarial plants: A community based survey. Journal of Ethnopharmacology, 132(1), 362-364.

Bennett, B.C. \& Husby, C.E. (2008). Patterns of medicinal plant use: An examination of the Ecuadorian Shuar medicinal flora using contingency table and binomial analyses. Journal of Ethnopharmacology, 116, 422-430.

CFDA, (2014). CDFA Announcement 2014 No.1. China Food and Drug Admission, China.

Chinese Pharmacopeoia Commission, (2015). Chinese Pharmacopoeia 2015 (Chinese Edition). Beijing, China: China Medical Science Press.

Balick, M.J. and Cox, P.A. (1996). Plants, People, and Culture: The Science of Ethnobotany. Scientific American Library, New York

Bertea, C.M., Azzolin, C.M.M., Bossi, S., Dogli, G., \& Maffei, M.E. (2005). Identification of an EcoRI restriction site for a rapid and precise determination of $\beta$-asaronefree Acorus calamus cytotypes. Phytochemistry, 66(5), 507-514. 
ESRI (2011). ArcGIS Desktop: Release 10.4 Redlands, CA: Environmental Systems Research Institute.

Gorji A. (2003). Pharmacological treatment of headache using traditional Persian medicine. TRENDS in Pharmacological Sciences, 24(7), 331-334

Heinrich, M., Ankli, A., Frei, B., Weimann, C., And Sticher, O. (1998). Medicinal Plants In Mexico: Healers' Consensus And Cultural Importance. Social Science \& Medicine, 47 (11), 1859-1871

Heinrich, M., (1998). Indigenous Concepts of medicinal Plants in Oaxaca, Mexico: Lowland Mixe Plant Classification Based on Organoleptic Characteristics. Angewandte Botanik, 72, 75-81.

Hu S. (1989). The Authentic and Superior Medicinal Herbals in China. Harbin, China: Heilongjiang Science and Technology Publishing House.

Hu S. (1998). Illustration of the Chinese Herbs in the Place of the Genuine. Jinan, China: Shandong Science and Technology Publishing House.

Huang, J., Chen, J., Ying, J. \& Ma, K. (2011). Features and Distribution Patterns of Chinese Endemic Seed Plant Species. Journal of Systematics and Evolution 49(2), 8194.

Huang, L. \& Wang, Y., (2015). Theories and Prospects on Daodi Herbs. Modern Chinese Medicine, 17(8), 770-776.

Jamal, J.A., Ghafar, Z.A., \& Husain, K. (2011). Medicinal Plants used for Postnatal Care in Malay Traditional Medicine in the Peninsular Malaysia, Pharmacognosy Journal, 3(24), 15-24

Kala, C.P., Farooquee, N.A., \& Dhar, U., (2004). Prioritization of medicinal plants on the basis of available knowledge, existing practices and use value status in Uttaranchal, India. Biodiversity and Conservation, 13 453-13 469.

Kishore, G., Ranjan, S., Pandey, A., \& Gupta, S., (2010). Influence of altitudinal variation on the antioxidant potential of tartar buckwheat of Western Himalaya. Food Science and Biotechnology, 19(5), 1355-1363.

Leon, C. and Lin, Y., (2017). Chinese Medicinal Plants, Herbal Drugs and Substitutes: An identification guide. London, UK: Kew publishing.

Leonti, M., Stafford, G.I., Dal Cero, M., Cabras, S., Castellanos, M.E., Casu, L., Weckerleb, C.S. (2017). Reverse Ethnopharmacology And Drug Discovery. Journal of Ethnopharmacology, 198 (2017), 417-431

Letunic, I. \& Bork, P. (2016). Interactive tree of life (iTOL) v3: An online tool for the display and annotation of phylogenetic and other trees. Nucleic Acids Res, 44(W1), W242-5. doi: 10.1093/nar/gkw290.

Meng, Q., Niu, Y., Niu, X., Roubin, R.H., \&Hanrahan, J.R., (2009). Ethnobotany, phytochemistry and pharmacology of the genus Caragana used in traditional Chinese medicine. Journal of Ethnobiology, 24(3), 350-368.

Minitab 17 Statistical Software (2010). [Computer software]. State College, PA: Minitab, Inc. (www.minitab.com)

Moerman, D.E. (1991). The medicinal flora of native North-America — an analysis. Journal of Ethnopharmacology, 31(1), 1-42.

Moerman, D.E., Pemberton, R.W., Kiefer, D. \& Berlin, B. (1999). A comparative Analysis of Five Medicinal Floras. Journal of Ethnobiology, 19(1), 49-67.

Ouarghidi, A., Powell, B., Martin, G.J., De Boer, H., Abbad, A., (2012). Species substitution in medicinal roots and possible implications for toxicity of herbal remedies in Morocco. Economic Botany, 66, 370-382.

Pan, F., (2011). Daodi medicinal material is the essence of Chinese medicine-a review of the $390^{\text {th }}$ session of Xiangshan Science Conference. Beijing: Science Times. Qian, X. (1987). Foreword. Hu, S. The Authentic and Superior Medicinal Herbals in China (p.2). Harbin, China: Heilongjiang Science and Technology Publishing House. Qian, H. \& Jin, Y. (2016). An updated megaphylogeny of plants, a tool for generating plant phylogenies and an analysis of phylogenetic community structure. Journal of Plant Ecology, 9(2), 233-239.

R Core Team (2014). R: A language and environment for statistical computing. R Foundation for Statistical Computing, Vienna, Austria.

(a)

Revell, L.J. (2011). Phyphytools: an R package for phylogenetic comparative biology (and other things). Methods in Ecology and Evolution, 3, 217-223.

Saslis-Lagoudakis, C.H., Williamson, E.M., Savolainen, V., \& Hawkins, J.A. (2011). Cross-cultural comparison of three medicinal floras and implications for bioprospecting strategies. Journal of Ethnopharmacology, 135(2), 476-487.

Saslis-Lagoudakis, C. H., Savolainen, V., Williamson, E.M., Forest, F., Wagstaff, S.J., Baral, S.R., Watson, M.F., Pendry, C.A., \& Hawkins, J.A. (2012). Phylogenies reveal predictive power of traditional medicine in bioprospecting. Proceedings of the National Academy of Sciences of the United States of America, 109, 15835-15840.

Saslis-Lagoudakis C.H., Hawkins J.A., Greenhill S.J., Pendry C.A., Watson M.F., Tuladhar-Douglas W., Baral S.R., Savolainen V. (2014) The evolution of traditional knowledge: environment shapes medicinal plant use in Nepal. Proceeding of the Royal Society of London B: Biological, 281: 20132768.

Sivasankari, B., Pitchaimani, S., \& Anandharaj, M. (2013). A study on traditional medicinal plants of Uthapuram, Madurai District, Tamilnadu, South India. Asian Pacific Journal of Tropical Biomedicine, 3(12), 975-979. 
Shrestha, P.M. \& Dhillion, S.S. (2003). Medicinal plant diversity and use in the highlands of Dolakha district, Nepal. Journal of Ethnopharmacology, 86(1), 81-96.

Tan, X (2016). The Systematizations and Researches of Exotic Medicinal Plants (Masters dissertation). Peking Union Medical College, Beijing, China.

Tan, H., Hu, D., Song, J., Xu, Y., Ca,i S., Chen, Q., Meng, Q., Li, S., Chen, S., Mao, Q., \& Xu, H. (2015). Distinguishing Radix Angelica Sinensis from different regions by HS-SFME/GC-MS. Food Chemistry, 186, 200-206.

Uniyal, S.K., Singh, K.N., Jamwal, P., \& Lal, B. (2006). Traditional use of medicinal plants among the tribal communities of ChhotaBhangal, Western Himalaya. Journal of Ethnobiology and Ethnomedicine, 2(14). doi: 10.1186/1746-4269-2-14

van Andel, T.R., van't Klooster, C.I.E.A., Quiroz, D., Towns, A.M. , Ruysschaert, S., van den Berg, M. (2014). Local plant names reveal that enslaved Africans recognized substantial parts of the New World flora. Proceedings of the National Academy of Sciences of the United States of America, 111(50), E5346-E5353

Weber, E., Sun, S., \& Li, B., (2008). Invasive alien plants in China: diversity and ecological insights. Biol Invasions, 10, 1411-1429.

Weckerle, C.S., Ineichena, R., Huber, F.K., \& Yang, Y. (2009). Mao's heritage: Medicinal plant knowledge among the Bai in Shaxi, China, at a crossroads between distinct local and common widespread practice. Journal of Ethnopharmacology, 123(1), 213-228.

Xing, Y. \& Ree, R.H. (2017). Uplift-driven diversification in the Hengduan Mountains, a temperate biodiversity hotspot. Proc. Natl. Acad. Sci. USA, 114(17), E3444E3451.

Xue, J., Huang, L.F., Zheng S, Chen, S. (2013). Sulfur Fumigation, a Better or Worse Choice in Preservation of Traditional Chinese Medicine? Phytomedicine, 20(1), 97105.

Zhang, X. (2007). Vegetation map of the People's Republic of China 1:1 000 000. Beijing China: The Geological Publishing House.

Zhao, Z., Guo, P., \& Brand, E. (2012). The formation of Daodi medicine materials. Journal of Ethnopharmacology, 140(1), 476-481.

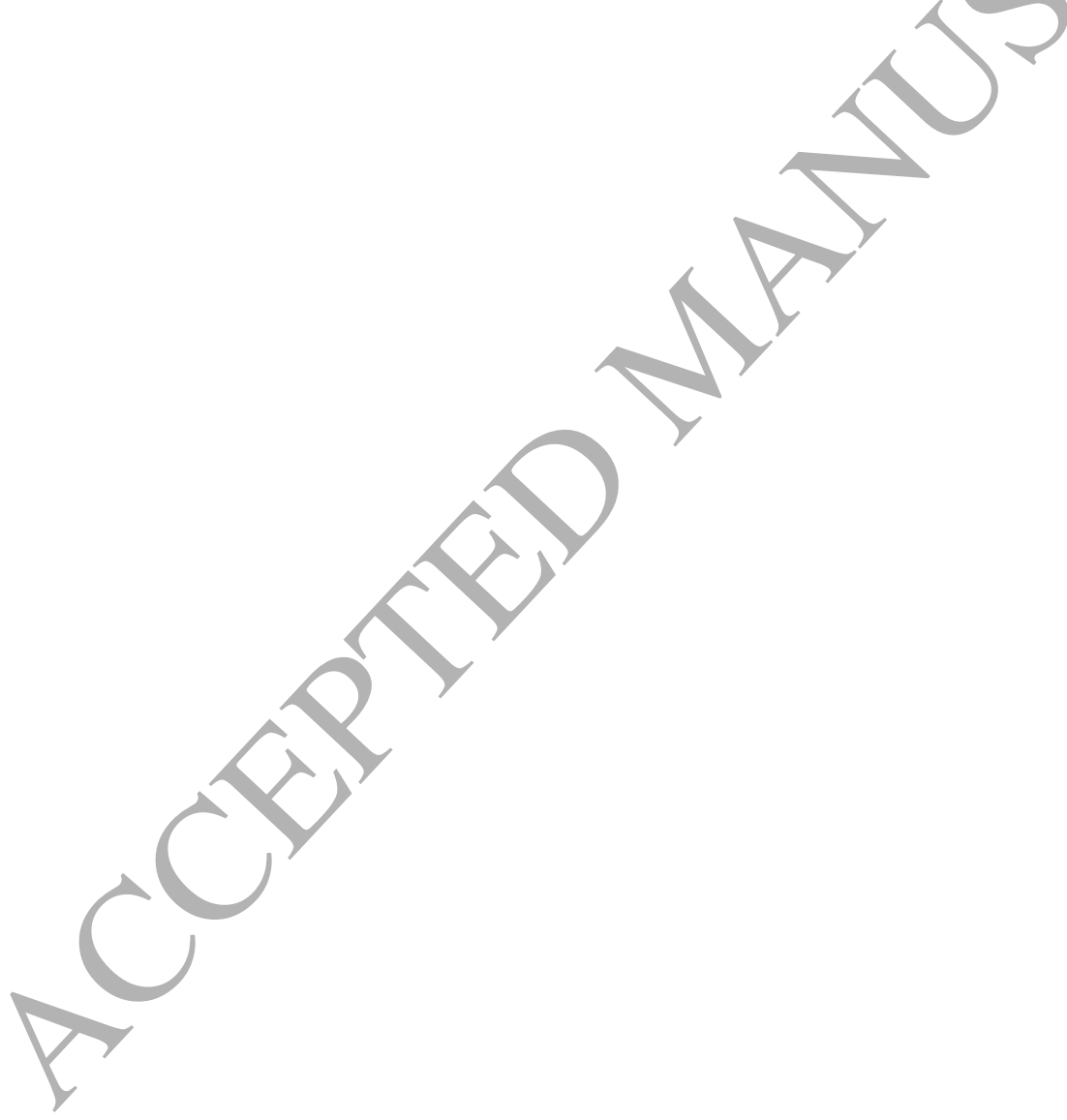




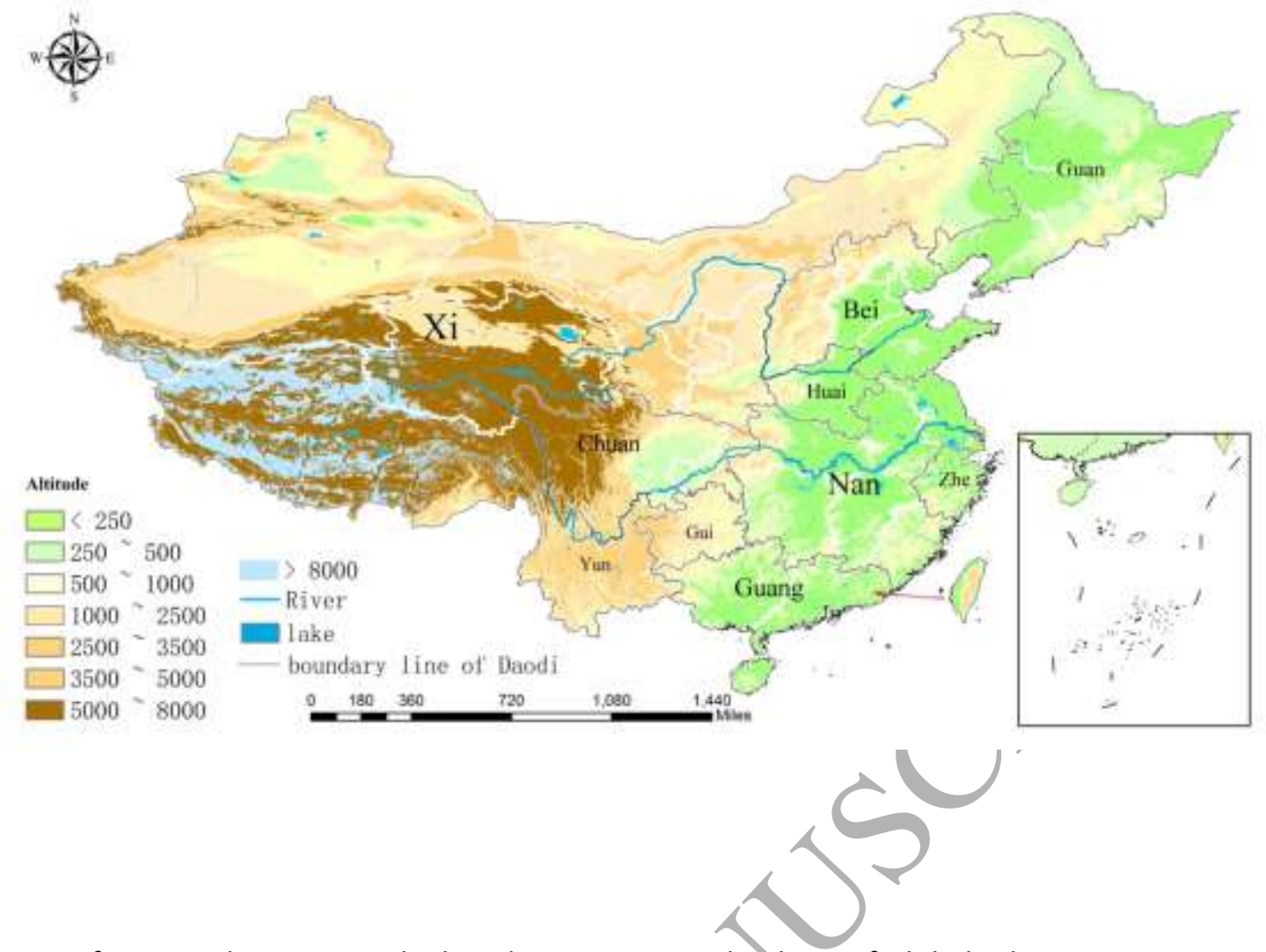

Fig.1. Map of ten Daodi regions with altitude using GADM database of Global Administrative Areas to delimit areas.

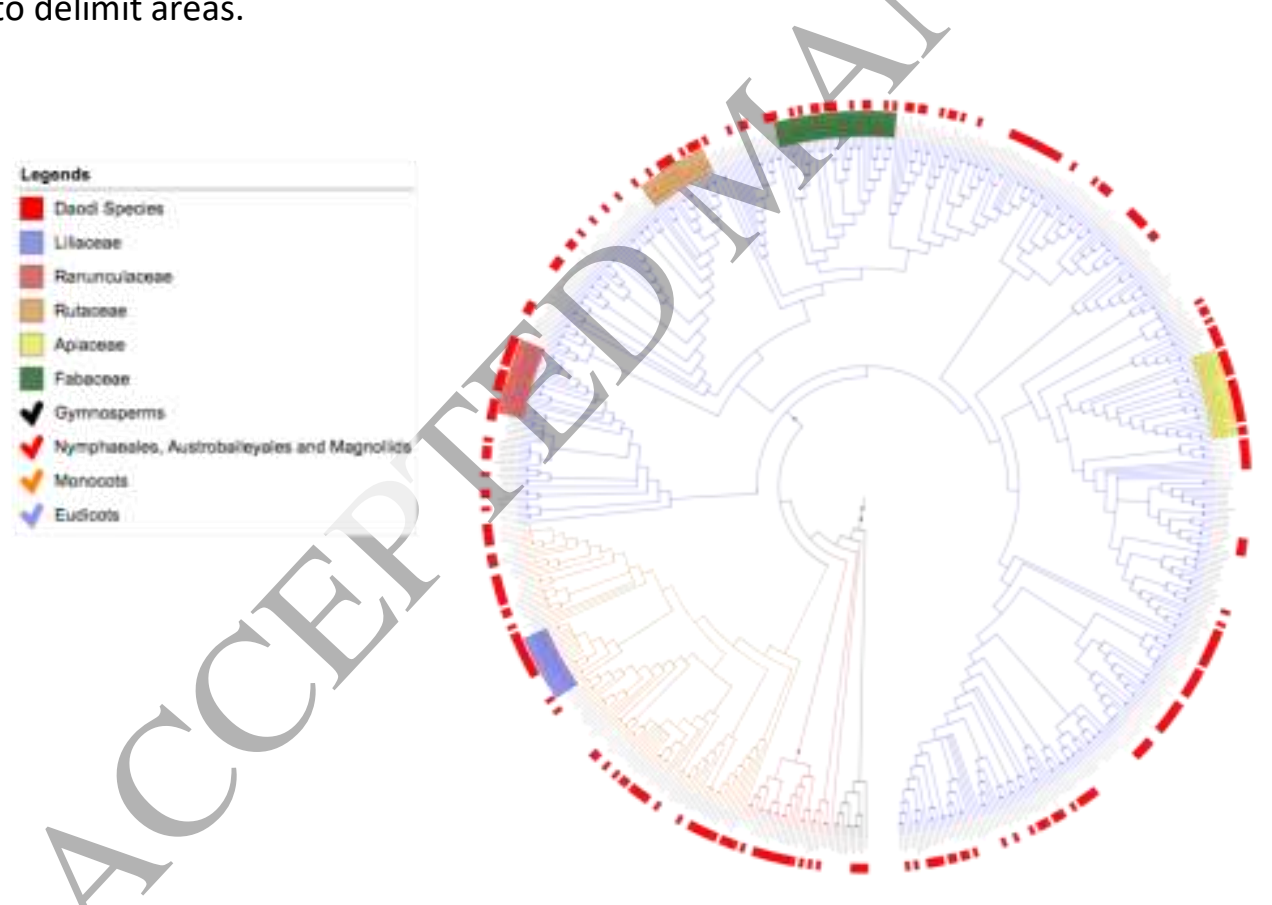

Fig 2. A phylogenetic tree for visualizing lineages preferentially selected for use in Chinese Pharmacopeia 2015 and Daodi medicinal material. Tree was constructed in R with package phylotool under function of S. phylomaker (Qian and Jin, 2015). 
Table 1: Administration, geographic position, climatical and ecological regions for 10 Daodi regions

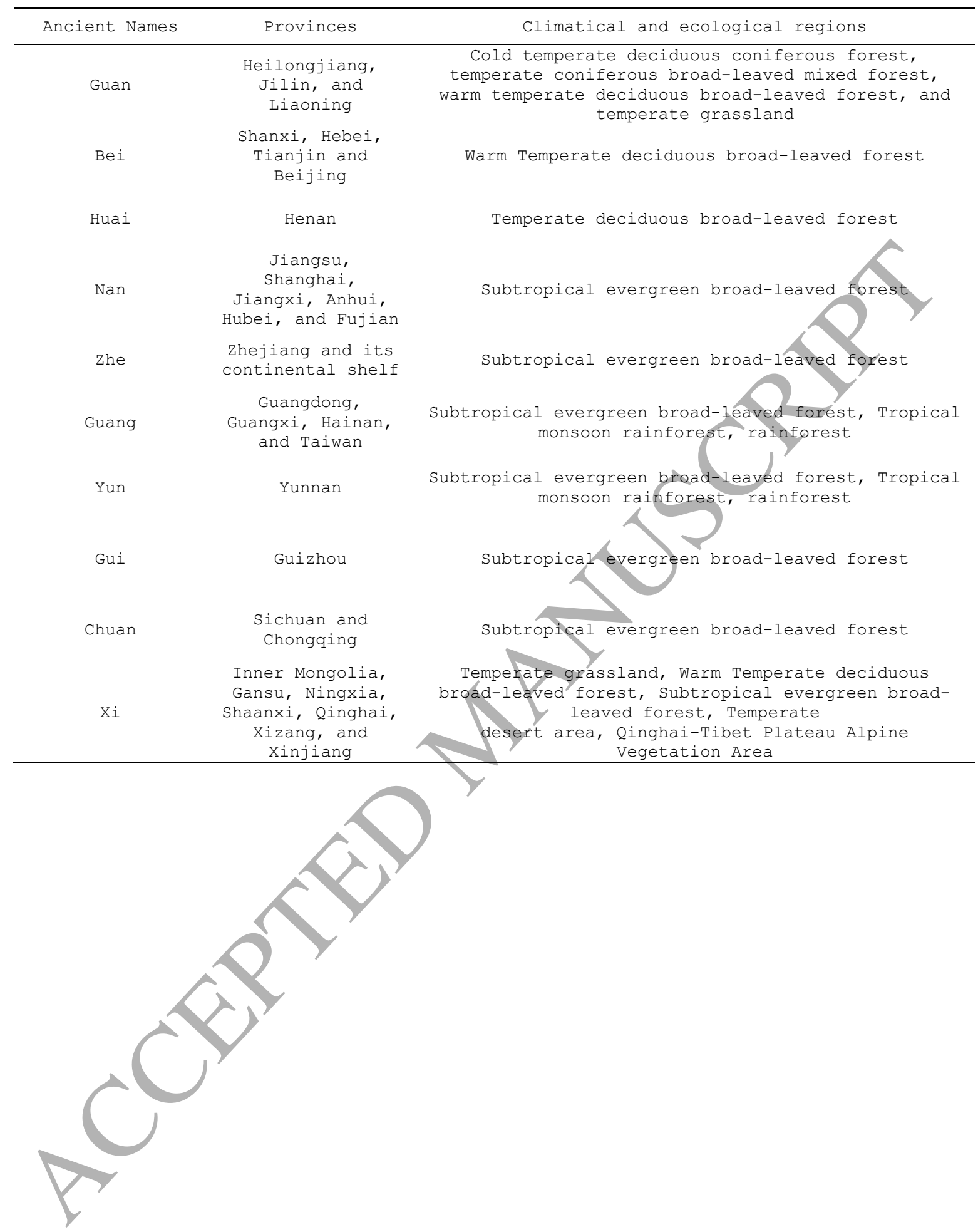


Table 2: Numbers of medicine for five categories of TCM traits and their distributions in 10 Daodi regions.

\begin{tabular}{|c|c|c|c|c|c|c|c|c|c|c|c|c|c|}
\hline \multicolumn{2}{|c|}{ Traits } & $\begin{array}{c}\text { CnPhar } \\
\text { m } \\
\text { exclud } \\
e \\
\text { Daodi }\end{array}$ & $\begin{array}{l}\text { Daod } \\
i\end{array}$ & Guan & Bei & $\begin{array}{c}\text { Hua } \\
i\end{array}$ & Nan & $\begin{array}{c}\mathrm{Zh} \\
\mathrm{e}\end{array}$ & Guang & Yun & $\begin{array}{c}\mathrm{Gu} \\
i\end{array}$ & Chuan & $X i$ \\
\hline \multicolumn{2}{|c|}{ No. Med } & 343 & 328 & 26 & 36 & 16 & 63 & 20 & 42 & 10 & 11 & 40 & 64 \\
\hline \multicolumn{2}{|c|}{ Toxic } & 50 & $\begin{array}{c}31 \\
\downarrow++\end{array}$ & 1 & 3 & 2 & 7 & 0 & 5 & 2 & $\begin{array}{l}3 \\
\mathbf{1}\end{array}$ & 8 & $\begin{array}{c}0 \\
\downarrow * \star *\end{array}$ \\
\hline \multicolumn{2}{|r|}{ Hot } & 2 & $\begin{array}{c}13 \\
\uparrow \boldsymbol{t}_{++}\end{array}$ & 1 & 0 & 0 & 0 & 0 & $\stackrel{4}{\uparrow}$ & 0 & & & 0 \\
\hline \multirow{7}{*}{ Nature } & Warm & 98 & $\begin{array}{c}119 \\
\mathbf{\uparrow}\end{array}$ & 11 & 10 & 6 & 25 & 8 & 17 & & & 4 & 24 \\
\hline & $\begin{array}{c}\text { Neutra } \\
1\end{array}$ & 62 & $\begin{array}{l}63 \\
++\end{array}$ & 1 & 8 & 2 & 9 & 1 & 5 & & & $\begin{array}{c}1 \\
\downarrow \star \star\end{array}$ & $\begin{array}{c}16 \\
\mathbf{t} \star \star \star\end{array}$ \\
\hline & $\mathrm{CoOl}$ & 32 & $\begin{array}{c}18 \\
+\end{array}$ & 1 & 1 & 0 & 4 & $\begin{array}{c}0 \\
\downarrow \star\end{array}$ & & 0 & 0 & $\begin{array}{c}0 \\
\downarrow * *\end{array}$ & 3 \\
\hline & Cold & 137 & 131 & 12 & 17 & 8 & 25 & 11 & 9 & & 3 & 20 & 21 \\
\hline & Sweet & 122 & $\begin{array}{c}132 \\
++\end{array}$ & $\begin{array}{c}5 \\
\downarrow *\end{array}$ & 13 & 9 & 25 & & & 4 & $\begin{array}{c}8 \\
\mathbf{t} \\
\star\end{array}$ & 10 & 33 \\
\hline & $\begin{array}{c}\text { Bitte } \\
r\end{array}$ & 195 & $\begin{array}{c}193 \\
++\end{array}$ & 15 & 20 & 8 & & & $\begin{array}{c}15 \\
\downarrow * \star \star\end{array}$ & 8 & 5 & $\begin{array}{c}31 \\
\uparrow \star \star\end{array}$ & 37 \\
\hline & $\begin{array}{c}\text { Pungen } \\
t\end{array}$ & 132 & 140 & 15 & 11 & 6 & & 11 & 18 & 1 & 3 & 19 & 25 \\
\hline \multirow{9}{*}{ Taste } & Acid & 23 & 19 & 1 & 3 & & & 3 & 1 & 2 & 0 & 0 & 2 \\
\hline & $\begin{array}{c}\text { Astrin } \\
\text { ge }\end{array}$ & 27 & $\begin{array}{l}20 \\
++\end{array}$ & 0 & 0 & & 5 & 2 & $\begin{array}{c}0 \\
\downarrow\end{array}$ & $\begin{array}{l}3 \\
\mathbf{1} \\
\star *\end{array}$ & 1 & 0 & $\begin{array}{c}9 \\
\mathbf{t} \star \star\end{array}$ \\
\hline & salty & 12 & $\begin{array}{c}18 \\
+\end{array}$ & 0 & 3 & 0 & 3 & 1 & $\begin{array}{c}7 \\
\uparrow * \star \star\end{array}$ & 0 & 0 & $\begin{array}{c}0 \\
\downarrow * *\end{array}$ & 4 \\
\hline & Weak & 10 & 4 & & 1 & 0 & 1 & 0 & 1 & 0 & 1 & 0 & 0 \\
\hline & $\begin{array}{c}\text { Sanji } \\
\text { ao }\end{array}$ & 1 & & & 0 & 0 & 0 & 1 & 0 & 1 & 0 & 0 & 0 \\
\hline & $\begin{array}{l}\text { Large } \\
\text { Intes } \\
\text { tines }\end{array}$ & 4 & & 5 & 10 & 3 & $\begin{array}{c}4 \\
\downarrow \star \star \\
\star\end{array}$ & 2 & 9 & 3 & $\begin{array}{c}0 \\
\downarrow \star \\
\star\end{array}$ & 8 & $\begin{array}{l}19 \\
\uparrow *\end{array}$ \\
\hline & $\begin{array}{l}\text { Small } \\
\text { Intes }\end{array}$ & & 14 & 3 & 2 & 0 & 3 & 0 & 0 & 0 & 0 & 3 & 3 \\
\hline & & & $\begin{array}{l}74 \\
++\end{array}$ & $\begin{array}{c}13 \\
\mathbf{\uparrow} \star *\end{array}$ & 9 & 3 & $\stackrel{6}{\downarrow \star}$ & 6 & 7 & 1 & 0 & $\begin{array}{c}18 \\
\mathbf{t} \star \star \star\end{array}$ & 11 \\
\hline & & 3 & $\begin{array}{l}12 \\
\mathbf{\uparrow}\end{array}$ & 0 & 0 & 0 & 2 & 0 & 5 & 0 & 0 & 1 & 4 \\
\hline \multirow{6}{*}{$\begin{array}{l}\text { Target } \\
\text { organs }\end{array}$} & & 178 & $\begin{array}{c}153 \\
+\end{array}$ & $\begin{array}{c}5 \\
\downarrow \star \star \star\end{array}$ & 16 & 7 & 28 & 13 & $\begin{array}{l}27 \\
\mathbf{T} \star \star\end{array}$ & 6 & 6 & 13 & $\begin{array}{l}32 \\
\boldsymbol{\uparrow} \star\end{array}$ \\
\hline & Lungs & 139 & $\begin{array}{c}140 \\
+\end{array}$ & 13 & 17 & 10 & $\begin{array}{l}34 \\
\uparrow \star\end{array}$ & 11 & $\begin{array}{c}9 \\
\downarrow * \star \star\end{array}$ & 6 & 6 & 16 & $\begin{array}{l}18 \\
\downarrow \star \star\end{array}$ \\
\hline & $\begin{array}{c}\text { Kidney } \\
\text { s }\end{array}$ & 73 & $\begin{array}{c}84 \\
+\end{array}$ & 8 & 7 & 4 & 15 & 4 & $\begin{array}{c}17 \\
\mathbf{\uparrow} * \star \star\end{array}$ & $\begin{array}{c}0 \\
\downarrow *\end{array}$ & $\begin{array}{c}0 \\
\downarrow * \\
\star\end{array}$ & 9 & 12 \\
\hline & $\begin{array}{c}\text { Stomac } \\
\mathrm{h}\end{array}$ & 118 & $\begin{array}{c}119 \\
++\end{array}$ & 6 & $\begin{array}{c}20 \\
\mathbf{t} * * \\
*\end{array}$ & 9 & $\begin{array}{c}15 \\
\downarrow \star \star\end{array}$ & $\begin{array}{l}3 \\
\downarrow \star\end{array}$ & 20 & 4 & 4 & 19 & 18 \\
\hline & $\begin{array}{c}\text { Gallb } \\
\text { ladde } \\
r\end{array}$ & 15 & $\begin{array}{l}27 \\
++\end{array}$ & 3 & 4 & 0 & $\begin{array}{l}1 \\
\downarrow\end{array}$ & 0 & 1 & 1 & 1 & $\begin{array}{c}7 \\
\uparrow \star \star\end{array}$ & $\begin{array}{c}10 \\
\mathbf{t} * \star *\end{array}$ \\
\hline & $\begin{array}{c}\text { Splee } \\
n\end{array}$ & 93 & $\begin{array}{c}103 \\
+\end{array}$ & 7 & 10 & $\begin{array}{c}1 \\
\downarrow \star \star\end{array}$ & 17 & 8 & $\begin{array}{l}16 \\
\mathbf{t}\end{array}$ & 2 & 2 & $\begin{array}{c}20 \\
\boldsymbol{\uparrow} \star \star \star\end{array}$ & 16 \\
\hline
\end{tabular}




\begin{tabular}{|c|c|c|c|c|c|c|c|c|c|c|c|c|c|}
\hline & $\begin{array}{c}\text { Bladde } \\
\quad r\end{array}$ & 23 & $\begin{array}{c}34 \\
\uparrow\end{array}$ & 7 & 2 & 0 & 9 & 1 & 5 & 0 & 0 & 4 & 6 \\
\hline Part & Aeria & & & & & & & & & & & & \\
\hline \multirow[t]{17}{*}{ of use } & 1 & & 15 & 0 & & & 6 & & 5 & & & & \\
\hline & $\begin{array}{l}\text { part } \\
\text { whole }\end{array}$ & 39 & $\downarrow \downarrow++$ & $\downarrow \star$ & 0 & 0 & $\boldsymbol{\uparrow} * *$ & 0 & $\star \star * *$ & 0 & 0 & 0 & 4 \\
\hline & plant & & & & & & & & & & & & \\
\hline & Bark & 8 & 16 & 1 & 0 & 0 & 2 & 0 & 1 & 0 & 1 & 5 & 6 \\
\hline & Flowe & & & & & 6 & & & & & & & \\
\hline & r & 33 & $\downarrow \downarrow \downarrow++$ & 0 & 0 & $\begin{array}{c}\mathbf{t} * \star \\
\star\end{array}$ & 2 & 0 & $\downarrow \star \star$ & 0 & 0 & * & 2 \\
\hline & $\begin{array}{c}\text { Fruit } \\
\text { seed }\end{array}$ & & & & & & & & & & & & \\
\hline & and & 80 & 84 & 2 & 15 & 3 & 17 & 3 & 17 & 2 & 3 & & 13 \\
\hline & parts & & & & & & & & & & & & \\
\hline & Leaf & 26 & 18 & 0 & 3 & 0 & $\begin{array}{c}9 \\
\boldsymbol{\dagger} * *\end{array}$ & 0 & 0 & & & & 5 \\
\hline & & 20 & ++ & $\downarrow \star$ & . & & $\star$ & & & & & & \\
\hline & Resin & 10 & 3 & 0 & 0 & 0 & 0 & 0 & 1 & & & 0 & 2 \\
\hline & Bulb & 5 & 12 & 3 & 0 & 0 & 0 & 1 & & & & 6 & 2 \\
\hline & & 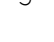 & ++ & $\star \star$ & 0 & 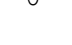 & * & 1 & & & & 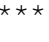 & 2 \\
\hline & Root & & 141 & 17 & & & & & & & & & \\
\hline & & 62 & $\uparrow \uparrow \boldsymbol{\uparrow}_{++}$ & $\mathbf{\uparrow} \star$ & 18 & 7 & 24 & & & & 6 & 17 & 24 \\
\hline & Stem & 38 & 30 & 3 & 0 & 0 & 3 & 0 & & 1 & 0 & 2 & 6 \\
\hline
\end{tabular}

For toxic, nature and part of use, all numbers represent single response, while for taste ańd target organ, numbers are recorded for multiple response results. CnPharm (Chinese Pharmacopoeia) column: " $\uparrow "$ " " $\downarrow$ " indicates numbers of medicine with those traits are statistically significant more/ less between Chinese Pharmacopeia 2015 (CnPharm) and Daodi medicinal material; Non-Daodi Column: " $\uparrow$ " “ $\downarrow$ ” indicates numbers of medicine with those traits are statistically significant more or less between Chinese Pharmacopoeia 2015 (CnPharm) excluded Daodi medicinal material (Non-Daodi) and Daodi medicinal material. " $\uparrow$ " “ $\downarrow$ " represents $P$ value is less than 0.05 in z test and in Fisher's exact test, " $\uparrow \uparrow$ " “ $\downarrow \downarrow$ " represents $P$ value is less than 0.001 in both tests. Daodi Column: "+" and "++" are below numbers, each of them indicates trait is statistically significant unequally distributed among 10 Daodi regions, "+" represents $P<0.05$ and "++" represents $P<0.01$, when $P$ value was found from their likelihood ratio with degree of freedom on 9. In 10 Daodi region columns: “***”, “**”, and “*” below each number highlights best, second and third contributor to likelihood ratio. 
Table 3 Positive and negative outliers recovered from regression analyses of Daodi species, and of Chinese Pharmacopoeia, compared to previous analyses of Nepal, South Africa Cape, and New Zealand (Saslis-Lagoudakis, 2011).

\begin{tabular}{|c|c|c|c|c|c|c|c|c|c|c|}
\hline \multirow{2}{*}{ Families } & \multicolumn{2}{|c|}{ Daodi } & \multicolumn{2}{|c|}{$\mathrm{CP}$} & \multicolumn{2}{|c|}{ Nepal } & \multicolumn{2}{|c|}{ SA Cape } & \multicolumn{2}{|c|}{ NZ } \\
\hline & $\mathrm{Re}$ & $\mathrm{Bi}$ & $\mathrm{Re}$ & $\mathrm{Bi}$ & $\mathrm{Re}$ & $\mathrm{Bi}$ & $\mathrm{Re}$ & $\mathrm{Bi}$ & $\mathrm{Re}$ & $\mathrm{Bi}$ \\
\hline Fabaceae & $6 *$ & $\star$ & 1 * & $\star$ & 1 * & $\star$ & 81 & & 32 & \\
\hline Rutaceae & $5 *$ & * & $2 *$ & $\star$ & 11 * & $\star$ & 47 & & 52 & \\
\hline Liliaceae & 1 * & $\star$ & $3 *$ & * & & & & & & \\
\hline Zingiberaceae & 4 * & * & 4 * & $\star$ & $13 *$ & $\star$ & & & & \\
\hline Rosaceae & $7 *$ & & $5 *$ & $\star$ & $17 *$ & & 126 & & 11 & \\
\hline Asteraceae & 46 & $\star$ & $6 *$ & $\star$ & $3 *$ & & $1 *$ & & & \\
\hline Lamiaceae & 11 * & & $7 *$ & & $2 *$ & $\star$ & $5 *$ & & & \\
\hline Apiaceae & $2 *$ & $\star$ & $8 *$ & $\star$ & & & & & & \\
\hline Cucurbitaceae & 12 & * & $9 *$ & * & $15 *$ & $\star$ & $23 *$ & & 68 & \\
\hline Ranunculaceae & $3 *$ & * & $10 *$ & & & & & & & \\
\hline Magnoliaceae & $10 *$ & $\star$ & $13 *$ & $\star$ & & & & & & \\
\hline Araliaceae & $8 *$ & * & $15 *$ & $\star$ & 85 & & & & $7 *$ & \\
\hline Araceae & $9 *$ & $\star$ & $22 *$ & & & & & & & \\
\hline Gesneriaceae & 118 & - & $117-$ & - & & & & & & \\
\hline Saxifragaceae & 117 & - & $118-$ & - & & & & & & \\
\hline Primulaceae & 119 & - & $119-$ & - & & & & & & \\
\hline Ericaceae & $121-$ & - & $120-$ & - & & & & & & \\
\hline Orchidaceae & 120 & - & $121-$ & - & & & & & & \\
\hline Cyperaceae & $122-$ & - & $123-$ & - & & & & & & \\
\hline Poaceae & $123-$ & - & $123-$ & & 197 & & $2 *$ & * & 116 & \\
\hline
\end{tabular}

"Re" columns: Regression analysis, Numbers show ranking of family in each ethnomedicinal flora, starting from one with largest residual value as recovered from regression analyses. Numbers followed by “*” indicate that family was recovered as a positive outlier in respective ethnomedicinal flora, "-" indicate as a negative outlier. "Bi" columns: Binomial analysis, "*” denotes that family has statistically more medicinal species than expected in flora, "-" denotes that family has statistically less medicinal species than expected in flora. Families with blank cells in both columns are not present in local flora, or they do not have positive residual in Saslis-Lagoudakis, 2011.

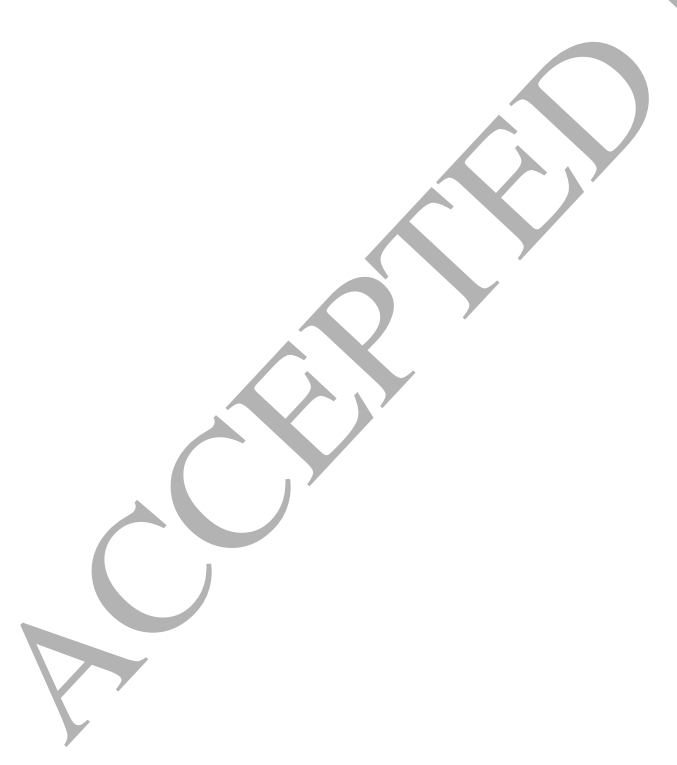


Table 4. Distribution of Chinese endemic species and invasive alien species to Chinese Pharmacopoeia, in each of Daodi regions and in Daodi overall.

\begin{tabular}{ccccc}
\hline Daodi Regions & Total Species & $\begin{array}{c}\text { Endemic } \\
\text { species }\end{array}$ & Endemic / \% & $\begin{array}{c}\text { Alien } \\
\text { invasive }\end{array}$ \\
\hline Guan & 25 & 3 & 0.12 & \\
Bei & 34 & 6 & 0.18 & 2 \\
Huai & 14 & 1 & 0.07 & \\
Nan & 57 & 9 & 0.16 & \\
Zhe & 11 & 3 & 0.27 & 1 \\
Guang & 34 & 7 & 0.21 & \\
Yun & 10 & 0 & 0.00 & \\
Gui & 8 & 2 & 0.25 & \\
Chuan & 32 & 10 & 0.31 & \\
Xi & 59 & 12 & 0.20 & 15 \\
Daodi & 284 & $53 *$ & 0.19 & 18 \\
Chinese Pharmacopoeia & 300 & 33 & 0.11 & 270 \\
excluding Daodi & & 86 & 0.15 & \\
Chinese Pharmacopeia & 584 & 15104 & 0.49 & \\
2015 & 31142 & & & \\
Flora of China & & & & \\
\end{tabular}

Figures for Chinese Pharmacopeia are also included for Chinese Pharmacopeia without Daodi, in other words for medicinal plants that are not Daodi. 
Appendix a: Regression equations and graphs for Chinese Pharmacopoeia and Daodi Species

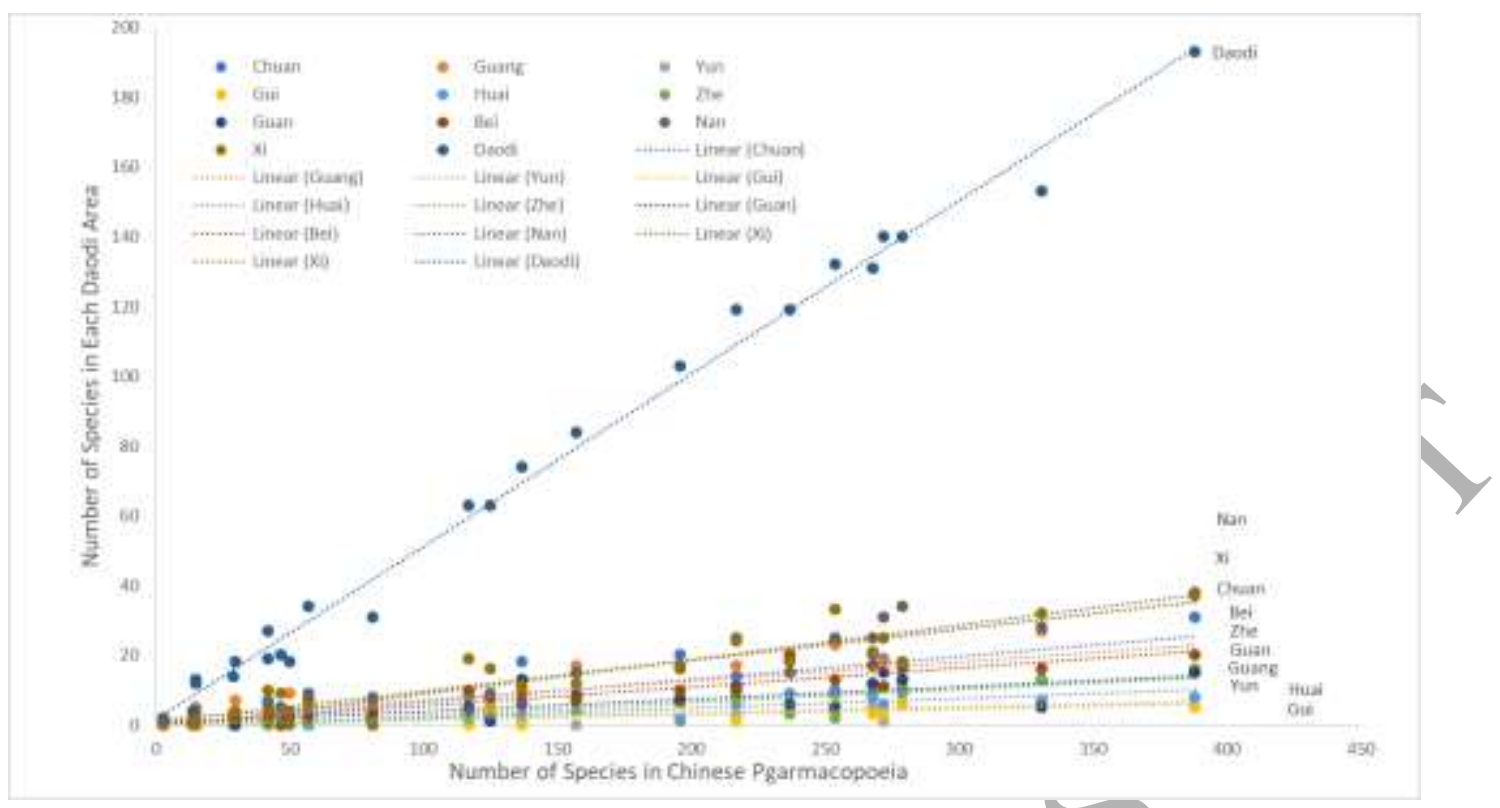

Linear Regression equations, from top to bottom: Daodi, $y=0,4962 x+1,4912 ;$ Nan, $y=0,0984 x-$ 0,8776; Xi, $y=0,0898 x+0,6981$; Chuan, $y=0,0652 x+0,1691 ;$ Bei, $y=0,0545 x+0,0636 ;$ Zhe, $y=$ $0,0375 x-0,9484$; Guan, $y=0,0353 x+0,5152$; Guang, $y=0,0549 x+1,7263$; Yun, $y=0,0163 x-0,0537$; Huai, $y=0,0281 x-0,6672 ;$ Gui, $y=0,0168 x+0,2395$ 